\title{
LOCAL AND GLOBAL MYTHS IN SHAKESPEAREAN PERFORMANCE
}

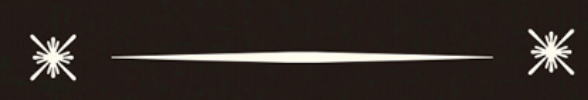

Edited by Aneta Mancewicz and Alexa Alice Joubin

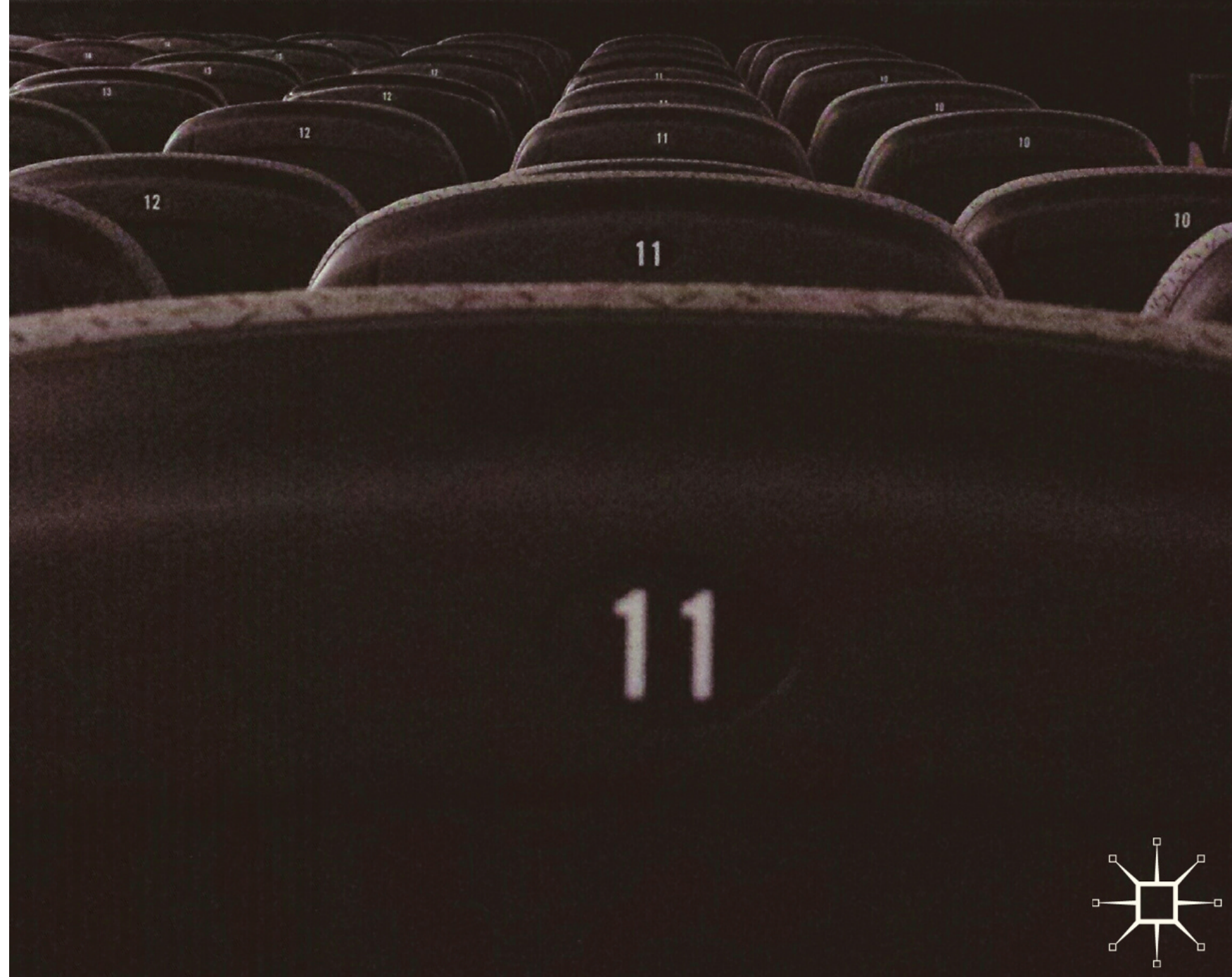




\title{
Shamanistic Shakespeare: Korea's Colonization of Hamlet
}

\author{
Kevin A. Quarmby
}

\begin{abstract}
SHAMAN 1: Poor souls. The dearly departed comes for a visit. [Now possessed] I'm here, I'm here. Today I borrowed this Shaman's body and lips to finally come see you.

$$
\text { [...] }
$$

Avenge me. My son, I shed tears of blood. (Hamlet 2010b, Act 1 Global Shakespeares Subtitles)
\end{abstract}

For the July 2014 City of London Festival, the Republic of Korea's Yohangza Theatre Company (yohangza meaning "voyager") travelled to the UK to stage a single performance of Hamlet at London's Peacock Theatre. Directed by the company's founder, Jung-ung Yang, Yohangza's Hamlet formed part of a three-week celebration of Korean culture called "Seoul in the City." Live performances by classical musicians and singers, contemporary dance and folk artists, as well as energetic B-boying street dancers, shared the festival programme in this one-off event. As the festival's director Paul Gudgin confirmed, Yang's showcase production was

K. A. Quarmby $(\bowtie)$

The College of St. Scholastica, Duluth, MN, USA

(C) The Author(s) 2018

A. Mancewicz, A. A. Joubin (eds.), Local and Global Myths in

Shakespearean Performance, Reproducing Shakespeare, https://doi.org/10.1007/978-3-319-89851-3_4 
chosen to highlight how "Korea is rapidly establishing a worldwide reputation as a cultural powerhouse" $(2014,5)$. Notable for foregrounding shamanism as the play's distinguishing characteristic, Yang's Hamlet could be considered a personalized projection of the director's Shakespearean aspirations. The local mythic imagery of shamanism, theatrically packaged for Western consumption, may illustrate the nation's intercultural propensity, but it hardly need define Korean culture globally. ${ }^{1}$

Individual as Yang's production might appear, Korean commentators have long recognized a creative impetus among late twentieth- and early twenty-first-century Shakespeare directors to integrate "traditional" shamanistic performance motifs to impart "authenticity" to their transnational exports. Li Lan Yong, for example, argued that such quests for authenticity lead to an "essentializing" notion of an "Asian collective identity" that is often "replicated," but with "some confusion" (2004, 251). More recently, Hyunjung Lee contends that decades of Koreanized Shakespeares, their "traditional heritage" based on an equally "essentialist, official framework of understanding," have almost entirely annulled Shakespeare's "epistemological formation" as a quintessential symbol of Western culture, while still endorsing the playwright's "brand name" $(2015,121)$. With regard to Yang's Yohangza productions, however, Lee sees such heritage-based Koreanizing, rather than hindering, as actually enhancing Shakespeare's "readability" for Korean and non-Korean spectators alike (2015, 121).

With Korean shamanism regularly disseminated and consumed in Shakespearean form, this chapter argues that, rather than enhancing their local and global "readability," Koreanized Shakespeares only confuse their audiences by concretizing shamanic myth as the reductionist key to interpreting all Asian versions of Hamlet. By shamanizing Shakespeare, the Korean theatre industry has effectively colonized Hamlet's iconic narrative, infusing it with a mythic construct that remains fluid and undefined. Associated with a longstanding artistic battle to impose an identifiable Koreanness on the nation's creative output, waged by an urban intellectual elite educated according to Western academic values, shamanism has been stripped of its rural identity. Internationally, Korea's mythic symbolism can seem confusing and impenetrable. Locally, Koreans find difficulty in accepting it as authentically theirs.

Although focusing on the Yohangza Hamlet as a crucial case study for appreciating the complex heritage of the Korean theatre industry's fascination with shamanistic Shakespeare, this chapter also invites far broader critical consideration about the inherent dangers of imposing a reformulated national myth — in this instance, Korean shamanism —on Shakespeare 
in general, and Hamlet in particular. By exploring Korea's nationalist obsession with lost shamanic culture through the creative lens of Hamlet, it is possible to interrogate Korea's colonizing of this particular play, repackaged in ritual re-enactment form, while investigating the transnational dissemination of local myth as a global Shakespeare phenomenon. To understand this re-exportation of Shakespeare as a quintessentially Korean cultural construct, we need to consider the unique historical, political, and social infrastructure of Korea, transmitted, in the context of Alexa Alice Joubin's introductory remarks, not as the "antithesis to the global or an antidote to the hegemonic domination [...] stereotypically associated with the West," but through the "complementary and irresolvable local differences" evident in the "site-specific epistemologies" of Korean drama. As a nation still recovering from the metaphorical exorcism of its mythical past by twentieth-century Japanese occupiers, Korea demonstrates how locality, history, and politics impact the "cultural powerhouse" pretensions of its present-day creatives.

Awareness of the forced acculturation of Korea by an all-dominant outside force must, however, be juxtaposed with the complex schizophrenic duality of Korea's shamanic mythic heritage. Indeed, nowhere is the duality of myths demonstrated in its absolute binary sense better than in Korea, where shamanism is culturally divided between the folkloric musok tradition of ecstatic performance, and the magico-religious mugyo tradition of local ancestor worship (Seo 2013, 76). Tracing back over five thousand years, Korean shamanism has for centuries jostled for national acceptance, especially after the arrival of the externally imposed doctrinal forces of Buddhism and Confucianism (Seo 2013, 21). For today's artistic exponents of shamanism, the folkloric musok (based on origin myth oral narratives) is prioritized as a national treasure, while the more contentious magico-religious mugyo (at odds with Korea's Christian community) is suppressed as incompatible with the nation's modernizing principles (Seo 2013, 46). Musok myth as folklore now dominates the shamanic scene. It is musok shamanism-superimposed on Koreanized Hamlet productions and re-exported globally-which is the principal focus of this chapter.

\section{Yohangza's Hamlet: A Mrthic Case Study}

Jung-ung Yang's London Hamlet was no new production. Instead, it reprised a theatre project first staged at Seoul's Myeongdong Theatre in 2009 as part of the Seoul Performing Arts Festival. As a freely available video confirms (filmed on the production's 2010 restaging for Adelaide's 
OzAsia Festival), the play's UK appearance remained faithful to this earlier version (Hamlet 2010b). London experienced the same staging, set design, and costumes, with its fourteen-strong cast and original starring "Hamlet," Yung-yong Jeon (Hamlet 2010a). Although occasionally filmed in less than ideal lighting conditions, the Australian recording mirrors precisely the play performed that damp Saturday evening to its attentive Peacock audience.

Attentive the audience needed to be. As Yohangza presented their fastpaced, localized evocation of Shakespeare's tragedy, resituated to a Gangnam-style Elsinore court replete with twenty-first-century fashion referents, Western eyes pondered the visual and aural significance of the play. Even before Hamlet made his first entrance-an undignified scrabbling around the stage prior to offering the production's Act 1 opening soliloquy, the resituated "To be or not to be, that is the question" (3.1.55) - this London observer was scribbling questions into his notebook. What was the significance of the boxlike three-sided set, selectively lit like a huge pictorial crossword puzzle, its colourful floor-to-ceiling building-block panels portraying images that evoked Eastern deities, spirits, and mythical figures? Why did the central acting area float in a sea of ivory-white rice, which later hindered the free movement of actors as it crunched noisily underfoot? What sounds would erupt from the weighty ethnic percussion instruments resting mute on either side of stage? Described by one Korean reviewer as filled with "heavily dense ritual atmospheres" that "instinctively" communicate Yohangza's shamanic intent, the archaic and unfamiliar imagery of stage designer Il-jin Im's exotic setting struggled to make its material voice heard in this postmodern English theatre space (Nam 2013, 270).

The unfamiliarity of these images, certainly for Western audience members, ensured that some felt geographically distanced and culturally disadvantaged before the play even began. As with several recent international ventures in London, most notably the 2012 Globe to Globe Festival, the expectation seemed that its Korean audience members would appreciate the play's localized nuances, while their globally inquisitive counterparts experienced some vicarious theatrical pleasure akin to Shakespearean intercultural voyeurism. Indeed, Yohangza's A Midsummer Night's Dream Globe to Globe appearance benefitted considerably from Li Lan Yong's retrospective analysis, which allowed Shakespeare Beyond English readers to appreciate fully the production's rhythmic Asian interactions $(2013,87)$. As such post-production analyses confirm, a certain level of globalized 
intercultural competence is required to appreciate the wave of international Shakespeare appropriations celebrated, for example, on the MIT Global Shakespeares website. For the 2014 Yohangza Hamlet, its nonKorean voyeurs were equally disadvantaged, although perhaps, in this instance, somewhat unnecessarily.

Unnecessarily because, at the production's 2009 premiere at the Seoul Performing Arts Festival, informative dual-language programme notes were provided as informational guidance (Hamlet 2009, 7-9). Indicative of Yohangza's acceptance that their shamanic imagery required explanation, these notes played a significant role in educating what presumably included a considerable homegrown Korean clientele. For Yohangza's 2014 restaging in London, no such notes were available. The only preproduction information came from a twenty-three-line half-page promotional statement in the seventy-six-page "Seoul in the City" calendar of events, presented free upon entry to the auditorium $(2014,29)$. With no theatre programme, these three short paragraphs were reduced to describing the play's "contemporary Korean language," and its "staging, costumes and music," all of which "integrates Korean tradition and shamanism" to construct "a performance of Hamlet like you have never seen it before" $(2014,29)$.

Despite the unwitting oxymoron of announcing this "never seen before" revival, the promotional material also references certain "traditional Korean $g u t$ rituals" as fundamental elements of the action (2014, 29). A "gut," so the festival calendar glosses, is "a ritualized special offering made by a mudang," in this instance represented by a "traditional Korean jinogigut ritual," held "so that Hamlet's father may pass smoothly into the afterworld" $(2014,29)$. Traditionally Korean these rituals may be, but there remained little information about their mythical significance, or the dramatic impact of such rites for Yohangza's non-Korean audience. Confused by the half-page commentary and eager to learn more, the author of this chapter turned to his London-based Korean student neighbour for enlightenment. What, I asked, was the significance of this Hamlet's "contemporary" realization, and what might the traditionally Korean examples of shamanism, gut ritual, or mudang offer Western audiences by way of a never-seen-before experience? Rather than a knowing explication of the production's culturally specific mythical heritage, this question led to a puzzled raising of the eyebrows. My young acquaintance's mystified response confirmed an equal unfamiliarity with these "traditional Korean rituals," especially the play's central theme, the jino- 
gigut. We were both, so it appeared, intercultural voyeurs, experiencing that same Li Lan Yong "confusion" over the authenticity of the play's traditional imagery $(2004,251)$.

Although this moment of unfruitful inquisition offers no more than anecdotal evidence of two people's cross-cultural confusion about a localized ritual re-enactment - and inevitable bewilderment until, after some post-performance online searching, the term mudang was clarified as a female shaman - it nevertheless highlights a Shakespearean instance of historicized "invasion" into contemporary Korean performances of Hamlet, according to Heiner Müller's "myth as an aggregate" equation (2001, 120). Müller might liken myth to a "machine to which always new and different machines can be connected," and which "transports the energy until the growing velocity will explode the cultural field," but the explosive energy of Yang's Hamlet - its self-referential foregrounding of a supposedly traditional Korean mythic ritual-seemed dissipated through its lack of recognition by English and Korean observer alike (2001, 120). Even the reviewer Peter Kirwan failed to grasp the material significance of the set design, his account opening with its description of a "raised platform thrust upwards from a bed of fine gravel," rather than the white rice with which Yang so consciously filled his stage (Bardathon 2014). The addition of shamanic ritual, gut exorcism, and symbolic rice might be considered an aggregated myth by Yang, but an appreciation of its localized cultural significance proved less than universal among audience members and reviewers, some of whom shared the same national heritage.

Perceived by some Koreans as an unhelpful attempt to bring a "dead tradition" back to life, and occasionally viewed as "more foreign" than the early modern English Hamlet on which it is based, theatricalized shamanic ritualism is far from universally accepted, even in Korea (Im 2008, 266). It seems surprising, therefore, that in discussion with theatre director Suna Choe, Yang should describe his Hamlet as a quintessentially "Korean play," designed to help Koreans "discover their identity" by allowing them to "think about the past, the present and the future" (Choe 2010). Although Yang denies vehemently any creative "goal" of "reenacting Korean traditions," he confirms a desire to "shed light on things that have always existed in the lives of Koreans" (Choe 2010). By focusing on the visual imagery of his "shrine," with its "simple stage decorated with rice," Yang explains how Hamlet encapsulates the timeless "harmony and spiritual relief" of Korean shamanism (Choe 2010). The cultural longevity and 
ubiquity of his stage properties confirm, for Yang, their shamanistic relevance to Hamlet.

Yang's prominent use of rice, mistaken for gravel by at least one London reviewer, is described more fully in a private email written only four days after the Peacock performance. Since rice "signifies both of life and death in Korean society," Yang explains, he decided to use it as a "kind of ritual offering that I devote to the stage of Hamlet" (Email 2014). Yang views his entire production - set design, actors, music, costumes, textual adaptation-as a shamanic devotional offering to Shakespeare's play. Since, as Yang asserts, all these "objects are usually used in shaman rituals," then the "play itself" is "none other than shamanism" (Choe 2010). Yang's creative logic, whereby the mere inclusion of shamanic objects unequivocally situates his Hamlet in Korean myth, while possibly overambitious in its transcultural expectations, is nonetheless explicable in the context of shamanism's "dynamic and performative" function-to use Aneta Mancewicz's description of staged myths-and exploitative appeal for Korea's elite and mass entertainment industries.

\section{Korean Shamanism as Theatrical Entertainment}

Yang's forceful denial about "reenacting Korean traditions" is understandable when considered alongside a cultural phenomenon that appears with some regularity on Seoul's mainstream theatre stages and national television channels (Choe 2010). Considered since the 1980s a protected folk tradition and performance art, shamanic rituals have become objects of cultural conservation, light entertainment, and tourist display. In consequence, state-sanctioned mudang conduct their gut ceremonies under the watchful protection of Korea's Cultural Conservation Law, their performances deemed "historically valuable" and "authentic" cultural properties rescued from extinction ( $\operatorname{Kim} 2003,208-9$ ). One such mudang, the renowned octogenarian Keum-hwa Kim, is the subject of a gut-inspired documentary film, Manshin: Ten Thousand Spirits (2014), shown at select arthouse festivals in the US and Canada. International exposure to these mudang National Living Treasures (or Human Cultural Treasures) as the state terms them confirms what Chongko Kim describes as the transformation of shamanism into a "distinct" performing arts "genre," staged by mudang practitioners who achieve local superstar status (2003, 217). 
The performative potential of shamanism as a generic art form is discussed fully in Phillip B. Zarrilli's Theatre Histories. In his section on performance in oral and written cultures before 1700, Zarrilli describes how, in early band, tribe, or chiefdom communities, single individuals assumed the role of "ritual specialists and/or shamans," the word originally derived from the Siberian Evenk peoples and the Tungus word saman, to describe a person in an ecstatic or altered state of consciousness $(2006,26)$. As "religious specialists," shamans could, it was believed, heal illnesses, counteract misfortune, or solve personal or social problems, although only after "entering a state of trance" to communicate with the "unseen world" (Zarrilli 2006, 26). The trancelike state of such "specialists," associated with shamanistic activities that extend from North and Central Asia, through China, to the southernmost regions of the Indian subcontinent, is significant, since it equates most closely to Western perceptions of shamanism in terms of possession, spirit worlds, and animism. Recent ethnological studies, which foreground the necessity for shamans to "perform" (i.e. demonstrate to their communities) their successful unseen-world interactions, confirm a revisionist opinion that shamanism relies heavily on actorly skills (Harvey 2010, 30). Nonetheless, the traditional view of the shaman totally possessed by a spirit or object still prevails, with the performance process elided from critical view.

In Korea, by contrast, where shamanism is associated with the ancient practice of ancestor worship, an openly acknowledged performance process developed in unique partnership with the shamanic ritual practitioners entrusted with its care. Populated by ancestral gods and deities, the unseen world of Korean religio-mythology contained the "progenitors of the royal family, and by extension of the nation as a whole" (Grayson 2002, 225). To its believers, Korean shamanism offers, therefore, a direct umbilical link with the nation's mythical first sovereign, Dangun (Chung 2014, 31). Associated with the union of the sky father and earth mother archetypes, the "Dangun Myth" celebrates the originating god, whose deific offspring share their bloodline with all Koreans. These same ancestral gods and deities are celebrated in the colourful enshrined paintings that cover the walls of shamanic ritual houses, recreated with block-like intensity for the Yohangza Hamlet set. As a "transmitter of divine agency," Laurel Kendall and Jongsung Yang explain, each painting represents a "sort of divine prosthesis" that can be used or set aside by its depicted god, but which relies entirely on the shaman's body, through mime or spoken utterance, as 
the "moving media" for the spirit's animated presence $(2015,159)$. Unlike shamans that conform to Western expectations for trancelike spirit mediumship, Korean shamans never lose consciousness or volition, their role instead consciously to "grasp the willful gods' intentions and appropriately perform them into being" (Kendall and Yang 2015, 159). Rather than being duped by shamanic performance, Korean ritual attendees acknowledge and applaud the mudang shaman's acting talents as skills that guarantee a divine spirit's active presence and participation.

Performativity even extends to the Korean word mudang, the first syllable of which, " $m u$," when written in its logographic banja character, is "formed by two horizontal lines (at the top and bottom, symbolizing heaven and earth), with a central vertical line uniting them; on either side, a human being dancing in the air" (Hogarth 1999, 2). The mudang's (Chinese-derived) written character thus describes "one whose dance links the material and spiritual realms" (Zarrilli 2006, 48). Because of her distinctively material and spiritual performative function, the Korean mudang developed, therefore, into a highly theatricalized female ritualist who incorporated dance, music, and earthy humour into her ceremonies (Zarrilli 2006,48 ). Female gendered because, in the context of a society historically steeped in phallocentrism, shamanic rituals offered space for a "bitter critique" of Korea's religious chauvinism by empowering women to express their rebelliousness as mudang or lay participants (Rhi 1993, 262).

Described by Western analysts as "predominantly a women's cult," with male participation an "anomaly," Korean shamanism was rejected by men who feared being perceived as "nervous or weak" by their families (Ware 1991, 140; Johnson 2000, 263). Shamanism became, in consequence, confined to its female sphere of influence. Aware of the continued dismissal of shamanism by contemporary Koreans who "regard it as a primitive superstition," the philologist Kyong-geun Oh blames such Western (or Westernized) studies for Korea's ignorance about shamanic ritual, forced, as the nation was, for over a century to look at its "traditional culture" through the "eyes of foreigners" $(2016,83)$. Explaining the historical context for shamanism's development as "The Religion of Women," with male involvement in the rituals restricted to acting as musicians or stage-managing assistants, Oh finds precedent in Confucianism, which sanctioned male-only mediation between the living and the dead (2016, 79-80). Such Confucian-patriarchal gender bias, imported to Korea in the fifteenth century, guaranteed that shamanism became a "space of liberation" for Korean women to practice their beliefs (Oh 2016, 77). Excluded 
from power by a ruling elite that embraced Confucianism, women found an alternative freedom of cultural expression when they acquired or inherited the mudang's performance skills.

The mudang's principal performative outlet, therefore, is the gut (or kut) ceremony, with the "traditional Korean jinogigut ritual" referenced by the "Seoul in the City" promotional material but one example (2014, 29). Defined in folkloric terms as an Underworld Entrance Ritual and considered specific to the Seoul region, the jinogigut offers a "colorful and complex mix of costumes, food, music, soliloquy and exchange of jokes," all "singularly focused" on guiding the dead to underworld peace (Chung $2013,87)$. With a dramatic structure that includes the mudang inviting, supplicating, and finally releasing the appeased spirit to the underworld, and non-shaman participants interacting, coaxing, pleading, or even bribing the dead with food, alcohol, or money, the jinogigut seems an appropriate and locally recognizable ritual for exploring Hamlet's ghost narrative (Zarrilli 2006, 49). Yang's decision to base the Yohangza Hamlet on a jinogigut relies, however, not only on the locational specificity of Korea's broader folklore belief system but also on a very specific localized evocation of Seoul's shamanic performance scene. To the outside world, Yang's Hamlet might be recognizable for its Asian-collective Koreanness, but in Korea this version's "readability" requires awareness of its regional specificity and the inherent Seoul-ness of Yohangza's theatrical creation.

A present-day manifestation of regional shamanic specificity might be the newly opened Seoul Museum of Shamanism (2016), built to incorporate a surviving city shrine and offering "traditional performances, cultural festivals and hands-on activities" (Dunbar 2016). Designed to keep "alive" shamanism's "authentic" role as the "very soul of Koreans," the Museum of Shamanism perpetuates the notion of an authentic and re-creatable cultural entity, not dissimilar to its reconstructed Globe counterparts elsewhere in the world (Dunbar 2016). Guaranteeing a space for visiting shamans to practice their performance art, the museum's folklorist director Jong-sung Yang lets them conduct their "authentic" rituals, "provided they seek prior permission and aren't too loud" (Dunbar 2016). Unfortunately, such reanimation of shamanic practice within the noisesensitive confines of high-rise urban Seoul, while ensuring shamanism's continued touristic appeal, can never restore shamanism's regional variety or supposed authenticity. 


\section{Hamlet, Han, and Anti-Japanese Sentiment}

Yang might hope his London audience would appreciate the appropriateness of his Hamlet's jinogigut ritualism but, in doing so, he betrayed a transnational disregard for the local implications of his Seoul-specific artistic choices. In consequence, Yang's private email exchange, where he explains that "Korean people have long believed that spirits can speak through some mediums," combined with his essentialist comment, "as you could see in my Hamlet," does little to contextualize or clarify the shamanic gut ceremony at its core (Email 2014). Indeed, Yang's accompanying explanation about shamanism's relevance to his project poses yet further cross-cultural conundrums. Claiming that shamanism's role was "to exorcise Hamlet's Han (deep agonies and regrets)," Yang adds that, even "though we can't find [this plotline] in the original text," he also wanted "Ophelia's Han to be exorcised through such a way" (Email 2014). What does Yang mean when he describes Hamlet's and Ophelia's "Han" and how might this inform the play's readability for an international audience?

Within the context of Yang's play, an exorcism for Hamlet seems consistent with Shakespeare's narrative. With the Shaman voicing the Act 1 Ghost, and Hamlet hearing his father's spirit crying, "Avenge me. My son, I shed tears of blood," shamanism seems an obvious theatrical analogy (Hamlet 2010b). An exorcism for Ophelia, however, adds a wholly different localized reading to the play's shamanic detailing. In the Yohangza production, the moment occurs during Ophelia's gut-inspired funerary rites, where her sorrowful utterances are expressed by the mediating mudang:

SHAMAN 1: [ Weeping and sobbing] Dear Brother. My poor brother.

What kept you? Why didn't you stop me?

I was so alone and lonely.

The water was cold, dark, and scary. I couldn't breathe. (Hamlet 2010b, Act 5 Subtitles)

The emotional intensity of the mudang's outpouring of grief certainly bridged the cultural and linguistic boundaries between Peacock Theatre performance space and audience. Nevertheless, such moments did little to explain the "deep agonies and regrets" of Hamlet, the Ghost, or Ophelia, other than as simplistic longings to move from a corporeal to less troubled 
spiritual existence. It is likewise unclear how Yang's additional Hamlet dialogue equates to an exorcizable "Han." Only an appreciation of Korea's troubled twentieth-century political and religious evolution can ensure an informed readability for Yohangza's Hamlet.

As the religious commentators James Newton Poling and HeeSun Kim confirm, han is an "ambiguous" Korean term that refers to the "longterm, often intergenerational, effects of unrelieved trauma on persons, families, and communities" $(2012,72)$. For Koreans, an unresolved han is believed to lead to depression, anger, rage, and revenge-resulting occasionally in the "escape and oblivion" of suicide—as well as a shared discontent with the status quo manifesting in social and political unrest (Poling and Kim 2012, 73). Referring to Korea's century of war, violence, disruption, and social "fragmentation," Poling and Kim conclude that han "expresses the tragic reality of the Korean experience" $(2012,73)$. With revenge and suicide as key features, it might appear obvious why Yang should equate han interculturally with Hamlet. Nonetheless, it does little to explain to non-Korean consumers the tragic imperative of Korea's ban, or the intergenerational significance it shares with Hamlet.

The tragic event which originally led to Korea's traumatized han identity was the forced and systemic acculturation, imperialist exploitation, and social domination by a nearby neighbour, whose coastline sits only 150 miles across the Korea Strait. Japan alone bears the guilt for Korea's all-consuming han, its hinomaru "circle of sun" assimilation policy comprising the long-term goal of "civilizing" the Koreans into subservient pseudo-Japanese non-citizens (Caprio 2009, 10). Japan's aggressive expansionism effectively eclipsed Korean cultural expression by imposing (or superimposing) Japanese culture in its stead. Annexed by Japan between 1910 and 1945 after many centuries of Sino-Japanese conflict over the region, Korea consequently suffered the near extinction of shamanism as it was forced to adopt the Shinto mythical practices of its overseers (Caprio 2009, 109).

After the defeat of the Japanese in 1945, Korea's intellectual, political, and urban elite, eager to exorcise the ghost of Japanese assimilation, embraced Western religious and cultural practices in protest. Most evident was the adoption of Korean Christianity, the theological conservatism of which demonstrates its followers' strict adherence to predominantly Protestant puritan beliefs ( $\mathrm{Pak} 2005,225$ ). The fundamentalist tendencies of a religion that, as Grayson contends, represents both the "localization of Christianity" within Korea, and the emergence of a distinctly "indigenous" 
religious movement called minjung sinbuk ("theology of the people"), also led to the continued persecution of shamanism by anti-superstition policymakers $(2006,22)$. Arguing that the Christian God's actions are in direct response to the suffering of the "mass of the people," exponents of minjung sinhuk combined the dual concepts of minjung (the people) and han to offer spiritual solace to Korea's burgeoning Christian population (Grayson 2006, 22). For a nation in which, according to its 2015 census, Christians still outnumber Buddhists by nearly two to one, the Westernization of the Korean belief system seems a significant factor in shamanism's post-Japanese era decline (Kim 2016).

\section{Korean Nationalism and Shamanic Reanimation}

In the decades after the Second World War, Korea's government added further to the decline of shamanism. During the 1960s, for example, the state-sanctioned Saemaul Undong (new community or "New Town") rural modernization movement successfully suppressed shamanic practices in the nation's more remote regions (Rhi 1993, 255). Through the 1970s and 1980s, however, alternative nationalist protest movements and student activist groups emerged, which sought to "recuperate" Korea's cultural identity by focusing on its folkloric past (Sorenson 2016, 492). Recognizing the subversive heritage of shamanism as a site for anti-establishment, anti-patriarchal dissent, these nationalist groups recreated "shamanistic rituals of resistance," while unwittingly commercializing these near-lost ancient practices with their "pseudo-intellectual or dilettante" quest for authenticity (Kim 2003, 210). By the 1990s, the shaman mudang superstar was born.

Promoted by exponents of nationalist protest and activism, the enduring notion of an authentic Korean shamanic identity ran parallel, however, with the surprising veneration of the English language among Korea's cultural elite. Such "linguistic imperialism," as Yeeyon Im terms it, found its artistic home in Korean productions of Shakespeare, the playwright treated with almost "reverential" respect by producers and consumers alike (2008, 271-2). Unusually immune to postcolonial ire because non-representative of Japanese oppression, Shakespeare became the shamanic medium for communicating Koreanness to theatre audiences as early as the mid-1970s. Employing themes, sounds, and images closely associated with shamanism, theatre directors embraced these ancient ritual elements to create distinctively Korean Shakespeare identities. Unfortunately, Im argues, the resulting 
shamanistic shorthand, although intended to celebrate the "advancement of national culture," was more often characterized by an "incoherent jumble" of images, sounds, and words, manufactured to create "exotic commodities for the Western gaze" $(2008,260)$.

As incoherent as this jumble of shamanized Shakespeares might appear, they served to define Korea's theatre scene for several decades. Indeed, of the 376 Shakespeare plays performed in Korea since 1990 alone, eightyeight have been versions of Hamlet, which equates to twenty-three per cent (Nam 2013, 265). More significantly, in the context of Yang's "never before seen" cultural construct, of these eighty-eight Hamlets, no less than twenty-four (more than a quarter) adopted shamanism as their main theme, incorporated gut ritual, and/or presented Ophelia as a mudang or in shamanic terms (Lee 2011,$104 ; 2012,542$ ). With gut ritual so prominent a feature of Korea's Shakespearean output, Yang's Hamlet can be seen to exemplify a trope so "over-performed" in Korea that it represents nothing more than a constantly "repeating theatrical cliché" (Nam 2013, 287). As yet another cultural re-construct of a self-referential mythic archaism, Yohangza's Hamlet perpetuates an authenticated shamanic tradition created, like so many before, to reinvigorate Korea's identification with its near-lost ancient past.

Any suggestion, therefore, that Yohangza's production represents a unique example of Korea's mythic identity is, as we have seen, demonstrably flawed, especially given the number of shamanized Hamlets that preceded it. Like the superstar mudang accorded National Living Treasure status, Hamlet seems likewise revered as a Korean cultural icon. Awareness of shamanism's clichéd repetition by Korean Hamlet creatives, while possibly informing the local readability of the play, does little, however, to alleviate audience confusion when exported globally. Created primarily by Seoul's urban theatre producers, and influenced by post-occupation nationalist pride, shamanized and Koreanized Shakespeares hardly equate to universal acceptance or appeal. It is not differences of interpretation that cause confusion, however, but the far subtler divide between Korea's urban and rural cultures, especially the latter's perceived role as archival repository for the nation's mythic past. Yang's shamanized Hamlet, with its Seoul-specific jinogigut ritualism, might pander to the aesthetic tastes of an artistically incestuous urban theatre producing and theatregoing elite. In so doing, however, it also perpetuates an "official framework" formulation of authentic Museum of Shamanism ritualism that is as culturally invasive as the anti-rural modernization policies that led to shamanism's near extinction. Like so many productions before, Yang's gut-inspired Hamlet seems 
tainted by homegrown cultural condescension-an insidiously localized, intellectual form of colonialism-that renders its shamanized Shakespeare culturally confusing.

Korean productions of Hamlet might fulfil their nationalist agendas by referencing a reconstituted ancient gut ritual, but it will take several generations of exposure to this mythic aggregate before all Koreans embrace and accept it as their collective own. In a broader context, the perceived cultural incompetence of Western audiences appears less significant when Shakespeare's influence on Korean theatre in general, and Hamlet in particular, is considered in all its political, historical, and local complexity. Should the readability of all international Shakespeare performances rely on such contextual and cultural specificity? Hopefully not. As participants in the global Shakespeare phenomenon, however, we must strive to look beyond our "eyes of foreigners" preconceptions to appreciate the locational integrity of such mythic colonizations of Shakespeare, each uniquely suited to its local environment.

\section{Note}

1. My thanks to Ann Thompson for her inspirational advice; to Yeeyon Im for sharing her work, local knowledge, and primary Yohangza material; and to Jung-ung Yang for his kind response to my culturally incompetent questioning.

\section{REFERENCES}

Caprio, Mark E. 2009. Japanese Assimilation Policies in Colonial Korea, 1910-1945. Seattle: University of Washington Press.

Choe, Suna. 2010. Experimental Spirit of Classical and Traditional Plays: Interview with Yang Jung-Ung. Yohangza Theatre Company. Published June 25. http:// eng.theapro.kr/?sub_num=61 \&state=view\&idx=126. Accessed 14 Aug 2017.

Chung, Myung-sub. 2013. Encyclopedia of Korean Folk Beliefs, Encyclopedia of Korean Folklore and Traditional Culture, vol. 2. Ed. Myung-sub Chung and Trans. Ha-yun Jung. Seoul: The National Folk Museum of Korea.

- 2014. Encyclopedia of Korean Folk Literature. Encyclopedia of Korean Folklore and Traditional Culture Vol. 3. Ed. Myung-sub Chung. Trans. Ha-yun Jung. Seoul: The National Folk Museum of Korea.

Dunbar, Jon. 2016. Shaman Museum Shows Korea's First Religion. The Korea

Times. Published July 6. http://www.koreatimes.co.kr/www/news/ nation/2016/07/116_208809.html. Accessed 19 Aug 2017.

Grayson, James Huntley. 2002. Korea-A Religious History. Abingdon: Routledge. 
- 2006. A Quarter-Millennium of Christianity in Korea. In Christianity in Korea, ed. Robert E. Buswell Jr. and Timothy S. Lee, 7-25. Honolulu: University of Hawai'i Press.

Gudgin, Paul. 2014. Welcome to the City of London Festival. Souvenir Programme: City of London "Seoul in the City" Festival, 22 June-17 July 2014. Official Programme. London: The City Arts Trust Limited.

Hamlet. 2009. Yohangza Theatre Company. Official Programme. Myeongdong Theatre, Seoul. Performed October 30-November 8.

- 2010a. Yohangza Theatre Company. Official Programme. OzAsia Festival, Adelaide Festival Centre. Performed September 15-18. http://a-s-i-a-web. org/productionfiles/42_YohangzaHamletAdelaideprogrammex.pdf. Accessed 7 Aug 2017.

- 2010b. Directed by Jung-ung Yang. Yohangza Theatre Company. Filmed September 18 at the OzAsia Festival, Adelaide Festival Centre. MIT Global Shakespeares Video and Performance Archive. Ed. Peter S. Donaldson and Alexa Alice Joubin. http://globalshakespeares.mit.edu/hamlet-yang-jung-ung-2010/. Accessed 1 July 2017.

- 2014. Directed by Jung-ung Yang. Yohangza Theatre Company. Performed July 12, Peacock Theatre, London.

Harvey, Graham. 2010. Animism Rather Than Shamanism: New Approaches to What Shamans Do (For Other Animists). In Spirit Possession and Trance: New Interdisciplinary Perspectives, ed. Bettina E. Schmidt and Lucy Huskinson, 16-34. London/New York: Continuum.

Hogarth, Hyun-key Kim. 1999. Korean Shamanism and Cultural Nationalism. Seoul: Jimoondang Publishing Co..

Im, Yeeyon. 2008. The Location of Shakespeare in Korea: Lee Yountaek's Hamlet and the Mirage of Interculturality. Theatre Journal 60: 257-276.

Johnson, David A.G., Jr. 2000. An Interview: Korea University Students' Opinion of the Role of Shamanism and Fortune-Telling in Korea, Recorded at Korea University Graduate School of International Studies, 11 July 2000. In The Role of Shamanism and Fortune-Telling in Korea, 262-265. New York: The Korea Society.

Kendall, Laurel, and Jongsung Yang. 2015. What Is an Animated Image? Korean Shaman Paintings as Objects of Ambiguity. Hau: Journal of Ethnographic Theory 5 (2): 153-175.

Kim, Chongho. 2003. Korean Shamanism: The Cultural Paradox. Aldershot: Ashgate.

Kim, Han-su. 2016. Protestant Christians Now Biggest Religious Group in Korea. The Chosunilbo. Trans. Jin-seok Shon. Published December 21. http://english. chosun.com/site/data/html_dir/2016/12/21/2016122101318.html. Accessed 19 Aug 2017.

Kirwan, Peter. 2014. Hamlet (Yohangza Theatre) @ The Peacock Theatre, London. Bardathon. Published July 13. http://blogs.nottingham.ac.uk/ bardathon $/ 2014 / 07 / 13 /$ hamlet-yohangza-theatre-the-peacock-theatrelondon/. Accessed 16 Aug 2017. 
Lee, Hyon-u. 2011. Shamanism in Korean Hamlets Since 1990: Exorcising Han. Asian Theatre Journal 28 (1): 104-128.

- 2012. The New Millennium Shakespeare in Korea. Shakespeare Review 48 (3): 533-564.

Lee, Hyunjung. 2015. Performing the Nation in Global Korea: Transnational Theatre. New York/London: Palgrave Macmillan.

Manshin: Ten Thousand Spirits. 2014. Directed by Chan-kyong Park. At9 Film. DVD.

Müller, Heiner. 2001. Shakespeare a Difference. In A Heiner Müller Reader: Plays, Poetry, Prose, ed. and trans. Carl Weber, 118-21. Baltimore/London: Johns Hopkins University Press.

Nam, Ji-soo. 2013. Performative Aspects in Yang Jung-ung's Hamlet in Terms of Adapting Gut Performance. Journal of Modern British and American Drama 26 (3): 263-290.

Oh, Kyong-geun. 2016. Korean Shamanism-The Religion of Women. International Journal of Korean Humanities and Social Sciences 2: 71-85.

Pak, Ung Kyu. 2005. Millennialism in the Korean Protestant Church. New York: Peter Lang.

Poling, James Newton, and HeeSun Kim. 2012. Korean Resources for Pastoral Theology: Dance of Han, Jeong, and Salim. Eugene: Pickwick Publications.

Rhi, Bou-Young. 1993. The Phenomenology and Psychology of Korean Shamanism. In Contemporary Philosophy: A New Survey, Asian Philosophy, vol. 7, ed. Guttorm Fløistad, 253-268. Dordrecht: Springer.

Seo, Jinseok. 2013. The Role of Shamanism in Korean Society in Its Inter- and Intra-Cultural Contacts. Dissertationes Folkloristicae Universitatis Tartuensis 20, University of Tartu Press, Tartu, Estonia.

Sorenson, Clark W. 2016. 'Imagining a Field Site': Preparing for Anthropological Fieldwork in South Korea in the mid-1970s. The Journal of Korean Studies 21 (2): 485-516.

Ware, James. 1991. The Use of Muga in Korean Shaman Kuts: A Case Study for the Application of Performative Language Theory in Cross Culture Hermeneutics. Intercultural Communication Studies 1 (2): 137-146.

Yang, Jung-ung. 2014. Private Email to Kevin Quarmby. July 16.

Yong, Li Lan. 2004. Ong Keng Sen's Desdemona, Ugliness, and the Intercultural Performative. Theatre Journal 56: 251-273.

- 2013. Intercultural Rhythm in Yohangza's Dream. In Shakespeare Beyond English: A Global Experiment, ed. Susan Bennett and Christie Carson, 87-91. Cambridge: Cambridge University Press.

Zarrilli, Phillip B. 2006. Performance and Theatre in Oral and Writing Cultures Before 1700: Oral, Ritual, and Shamanic Performance. In Theatre Histories: An Introduction, ed. Gary Jay Williams, 15-49. New York/London: Routledge. 